
The apple tree

Past decades: from the whole-tree

typology to detailed analysis of

flowering and fruiting

$\Leftrightarrow$ Concepts for tree management

... in a system

A societal concern: " growing more with less inputs $"$.

$\Leftrightarrow$ The interest of agroforestry 


\section{The apple tree}

\section{Whole-tree Typology (Lespinasse and Delort, 1986)}

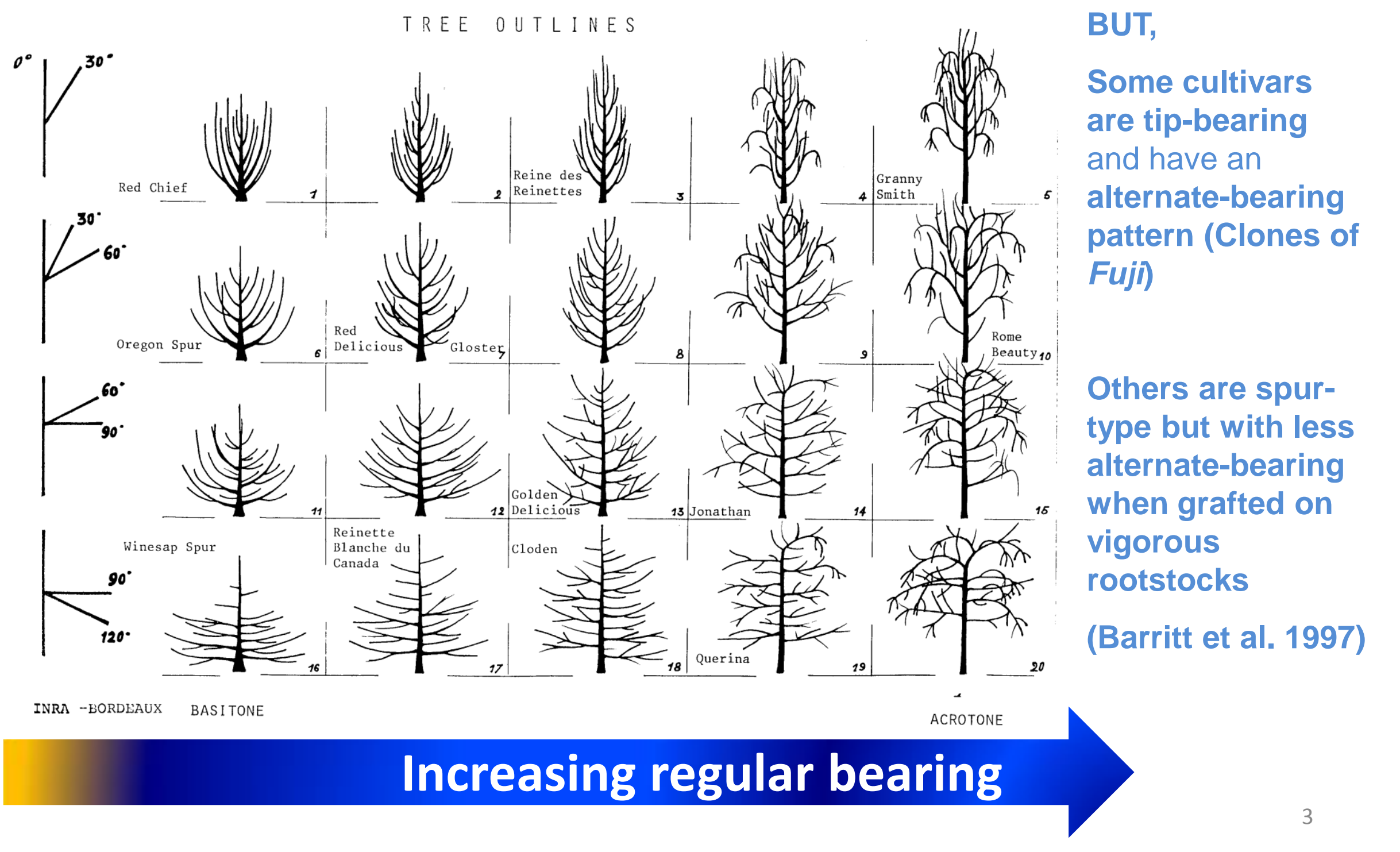


The apple tree

The need to develop

detailed analyses on

the flowering and

fruiting patterns

1- Where are the good fruits?

2- How can we manage the tree to get them? 
Towards a methodological framework for efficient research on apple tree architecture and physiology

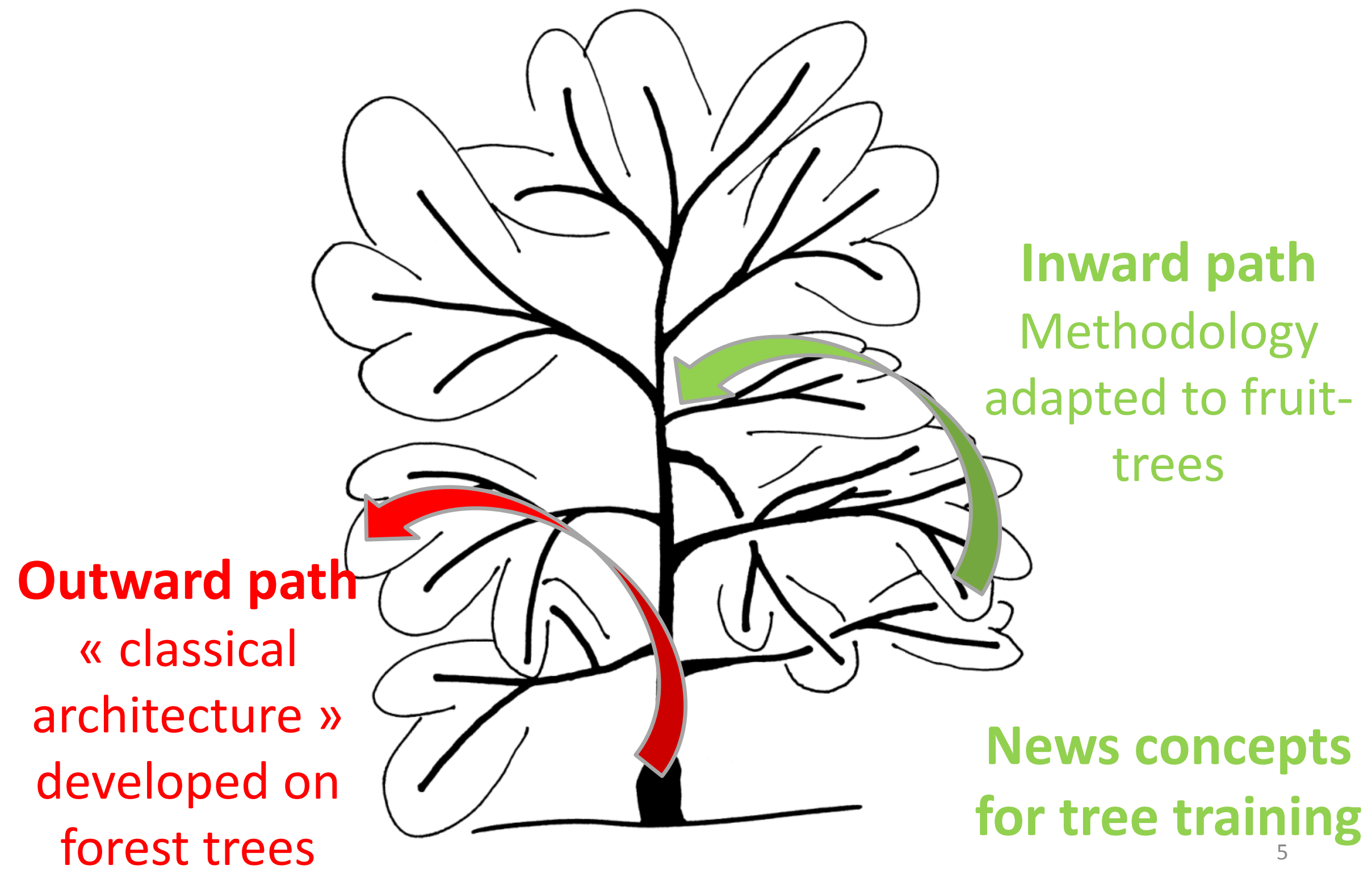




\section{Two Main results:}

$\checkmark$ What shoots to select?

$\checkmark$ Can we optimize pruning? 


\section{1 - Shoot length, fruit-set and fruit size}

\section{i.e., at least one fruit developed}

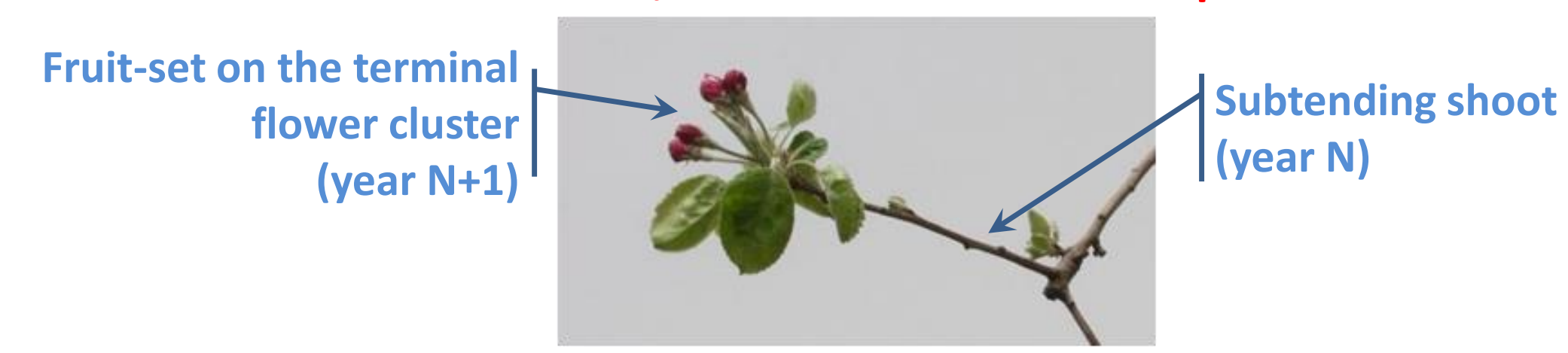

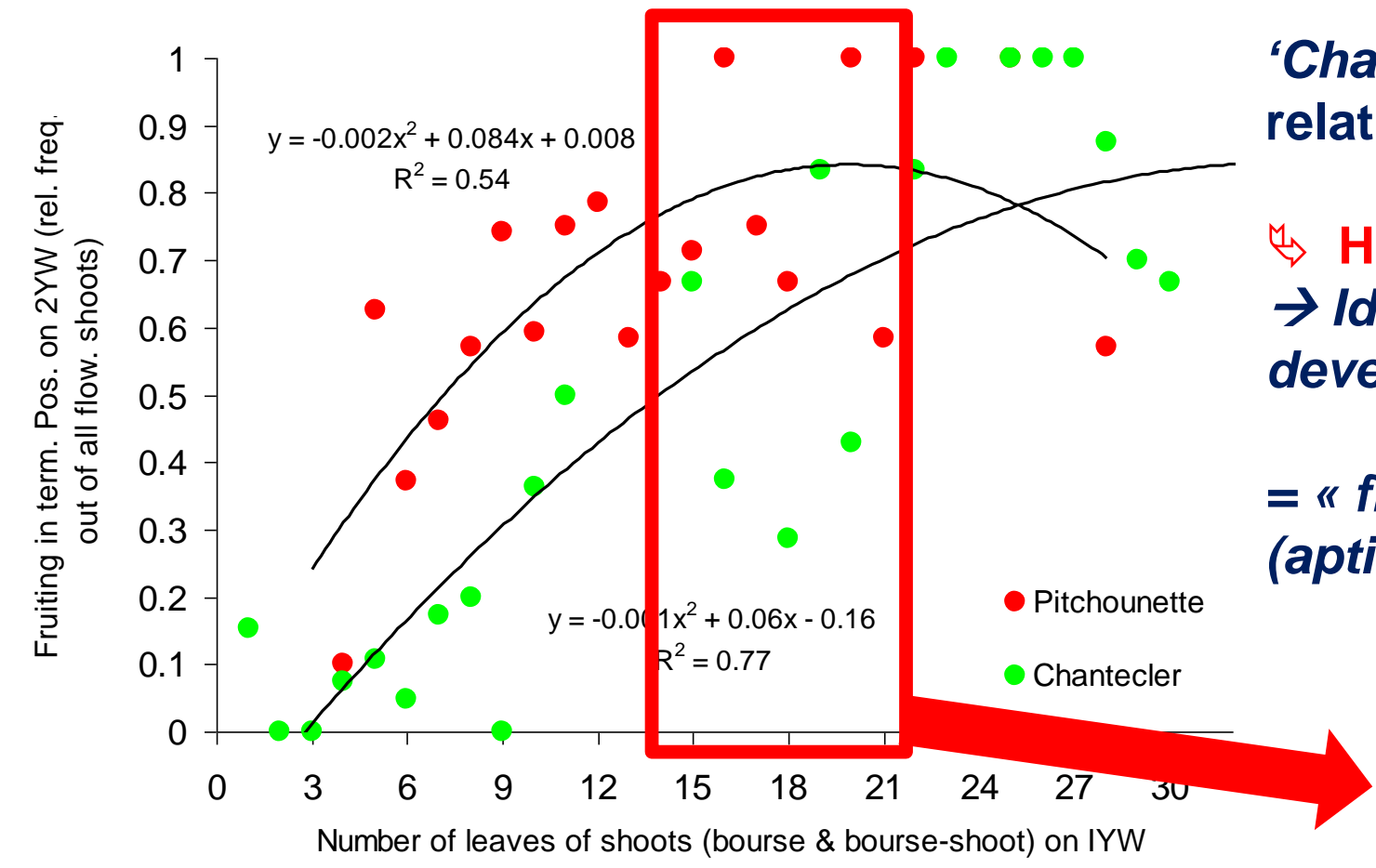

(Lauri \& Trottier 2004; Lauri \& Corelli-Grappadelli 2014)
"Crown brindle ": larger fruits on 10-20 cm-long shoots (Breen et al. 2007; Tustin et al. 2011) 


\section{2 - Spur extinction}

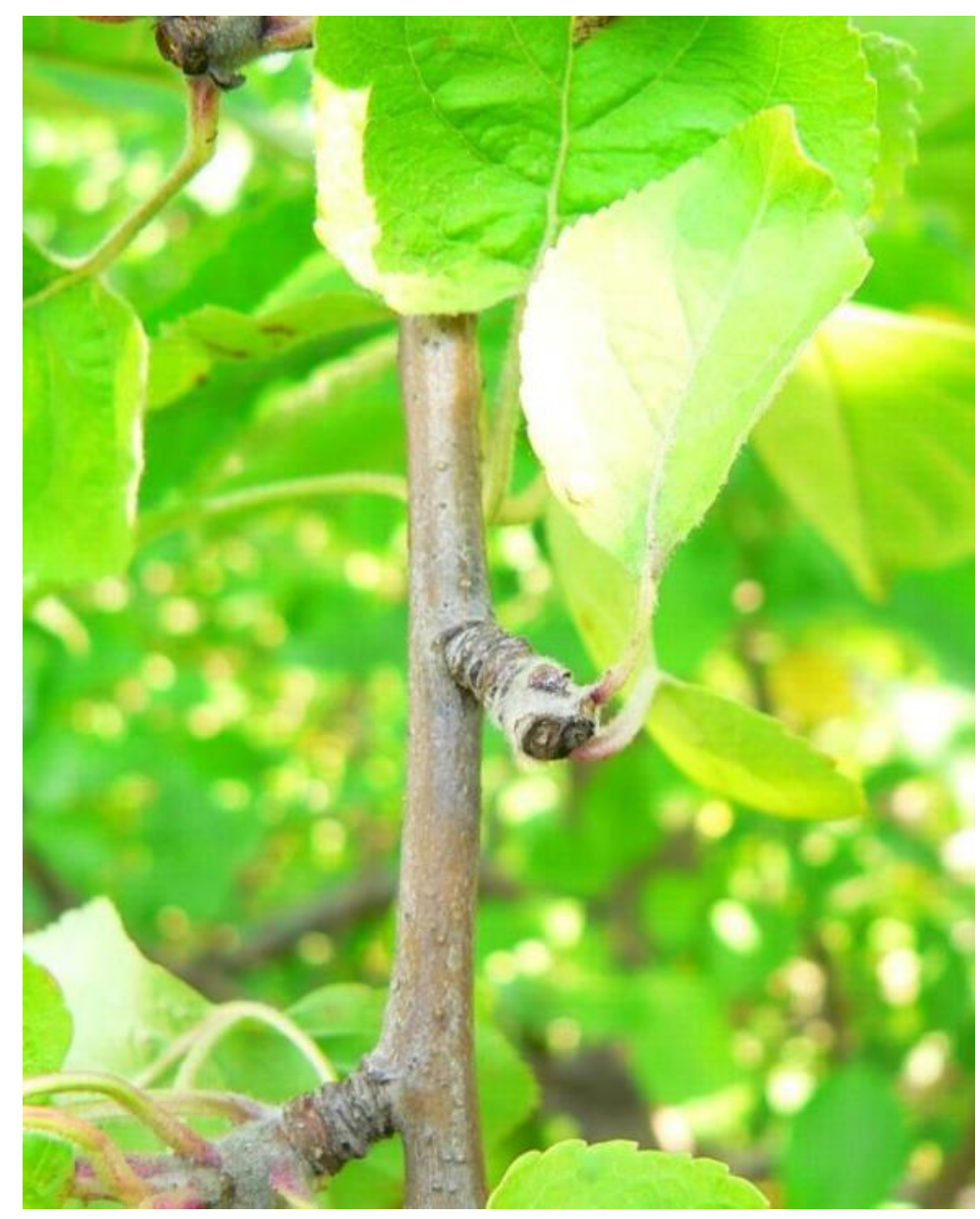

Physiological mechanisms?

Relations with hydraulics

(Han et al. 2007; Lauri et al. 2008)

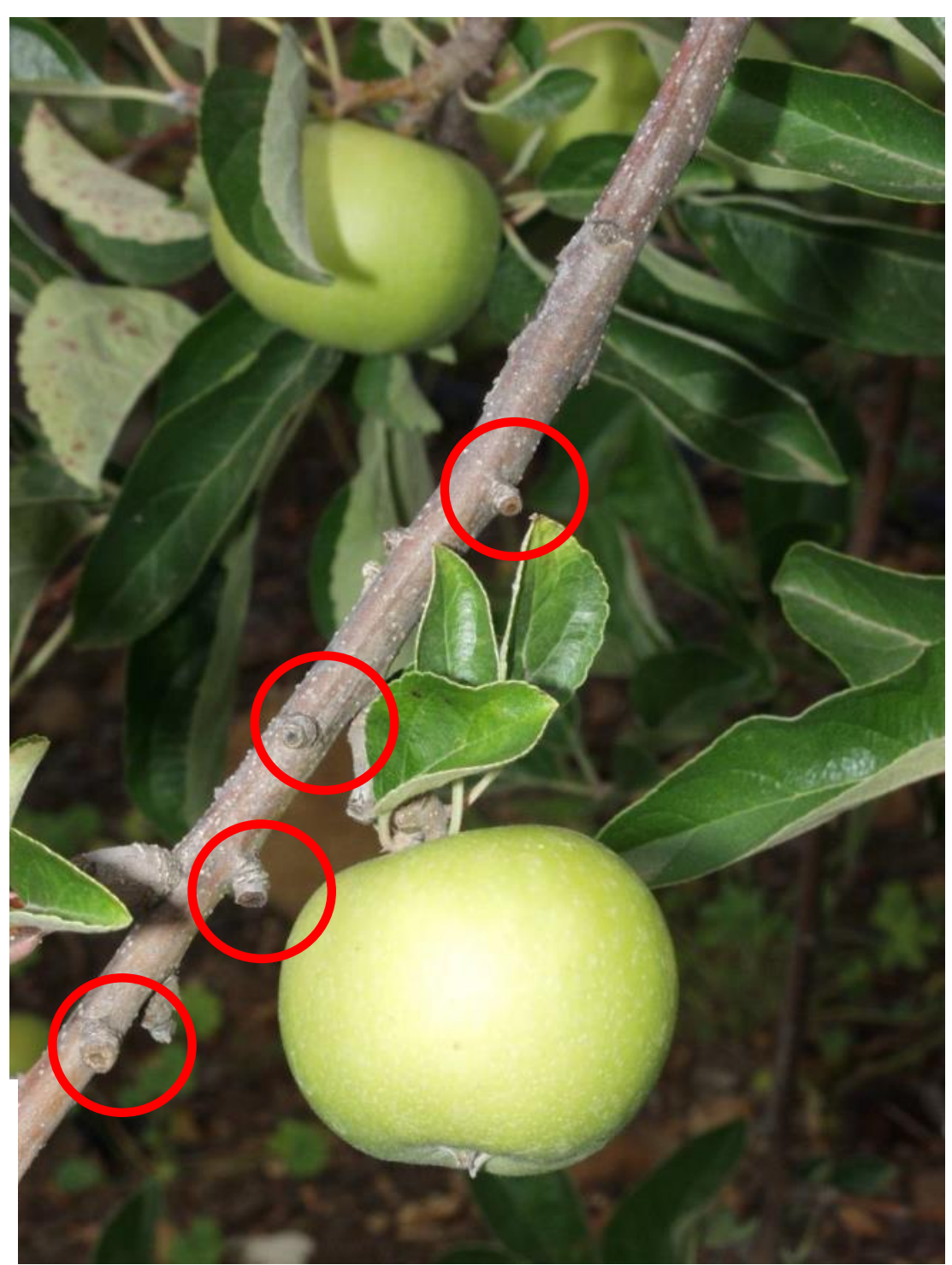




\section{3 - Extinction $\leftrightarrow$ Regular bearing}

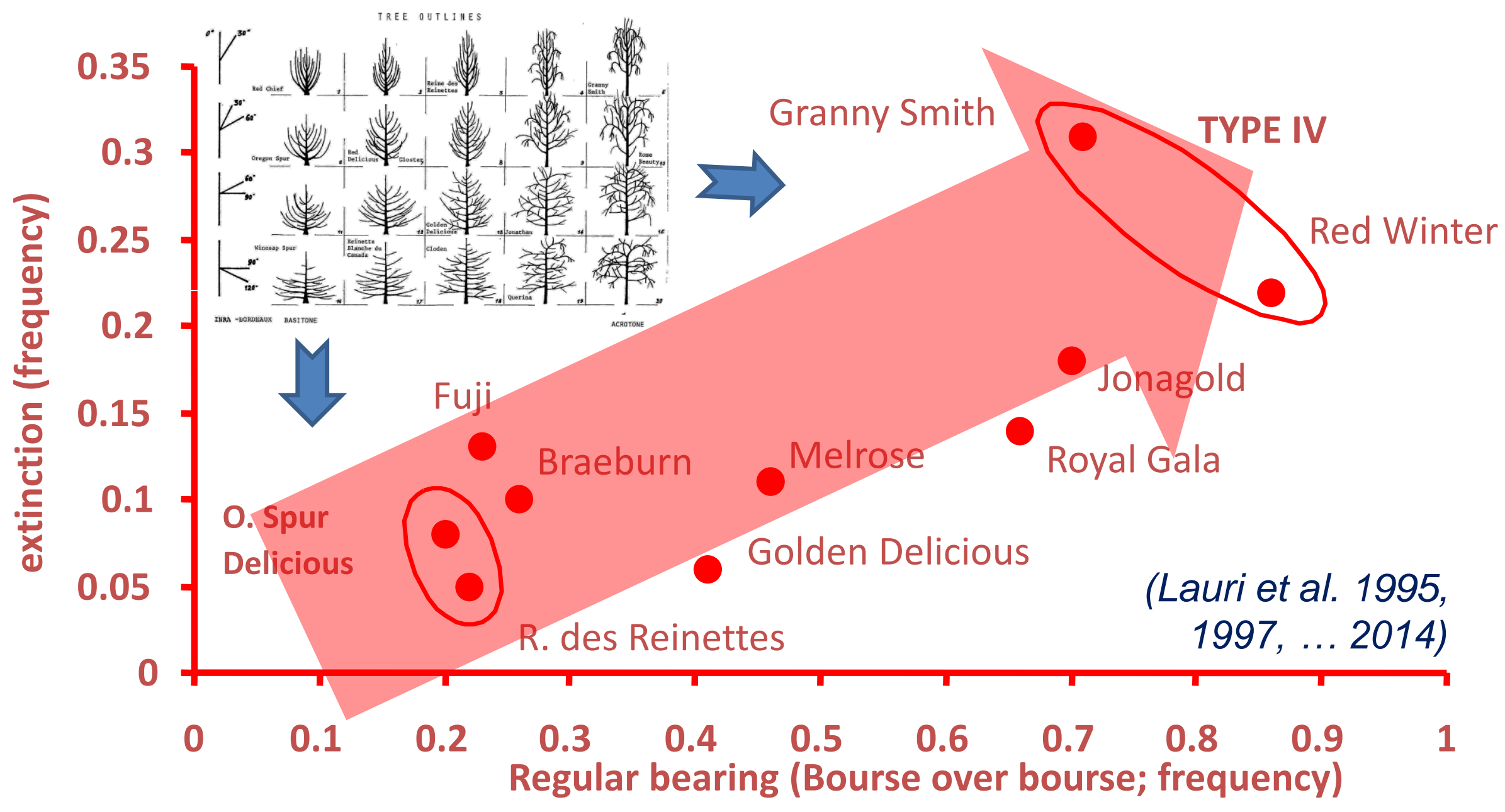

$\rightarrow$ Each cultivar has its own architectural strategy (shoot length, extinction,...) related to the fruiting pattern 
$\Leftrightarrow$ Results suggest a negative relationship between spur density and regular bearing.

$\stackrel{\leftrightarrow}{\rightarrow}$ Idea to do « artificial spur extinction " (ASE) on cultivars with alternate bearing to improve regular bearing and also to increase canopy porosity.

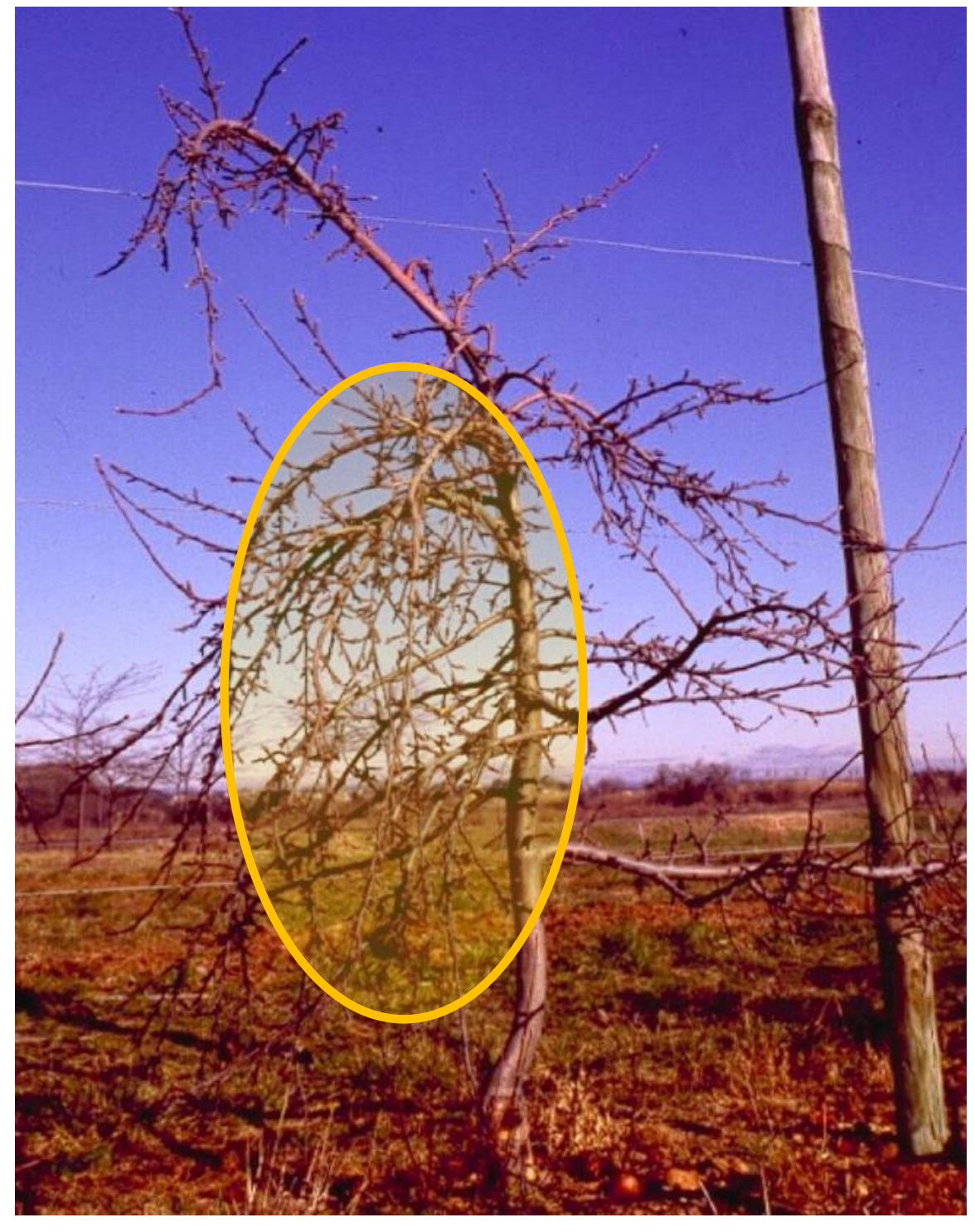

'Braeburn'/M19 


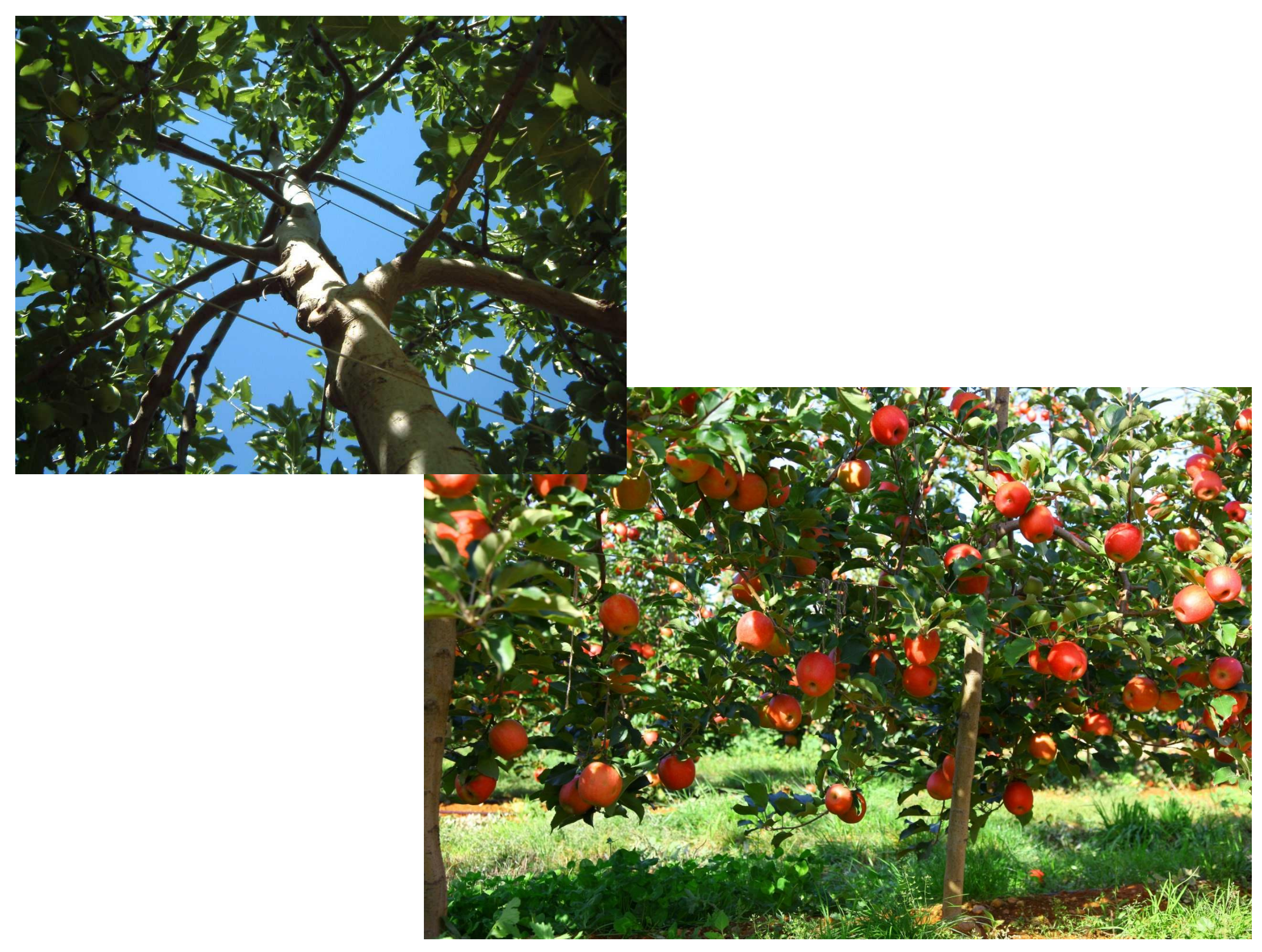




\section{Example: trend in France...}

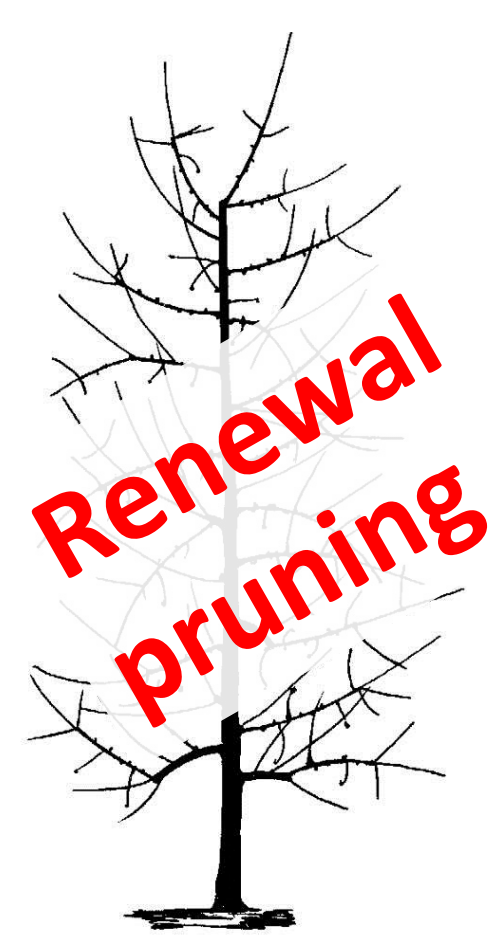

Vertical Axis

(Lespinasse 1977, 1980)

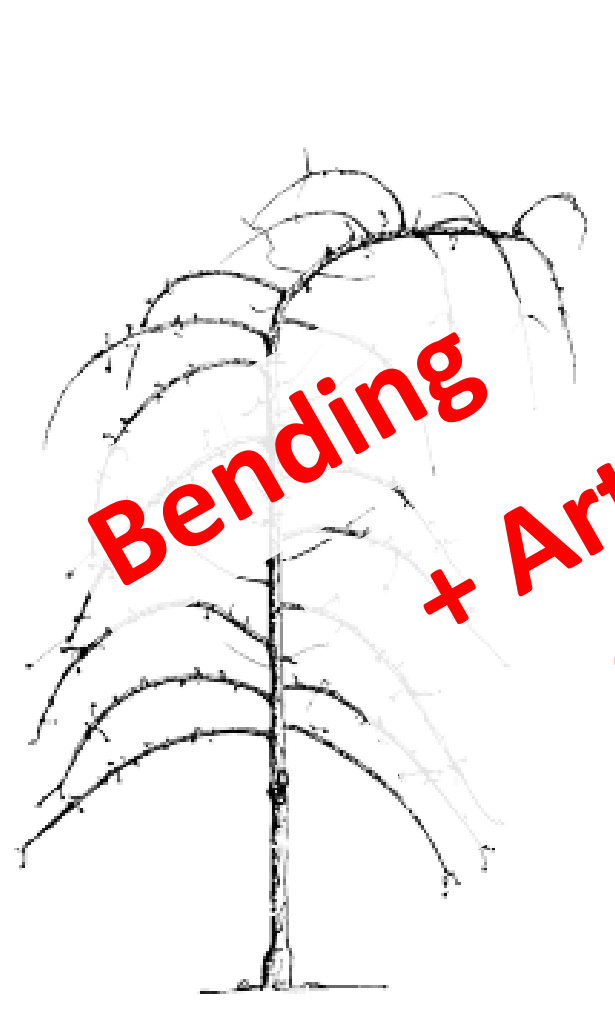

Solaxe

(Lespinasse \& Lauri 1996)

Paradigm:

" single trunk - fruiting branch - fruiting spur »

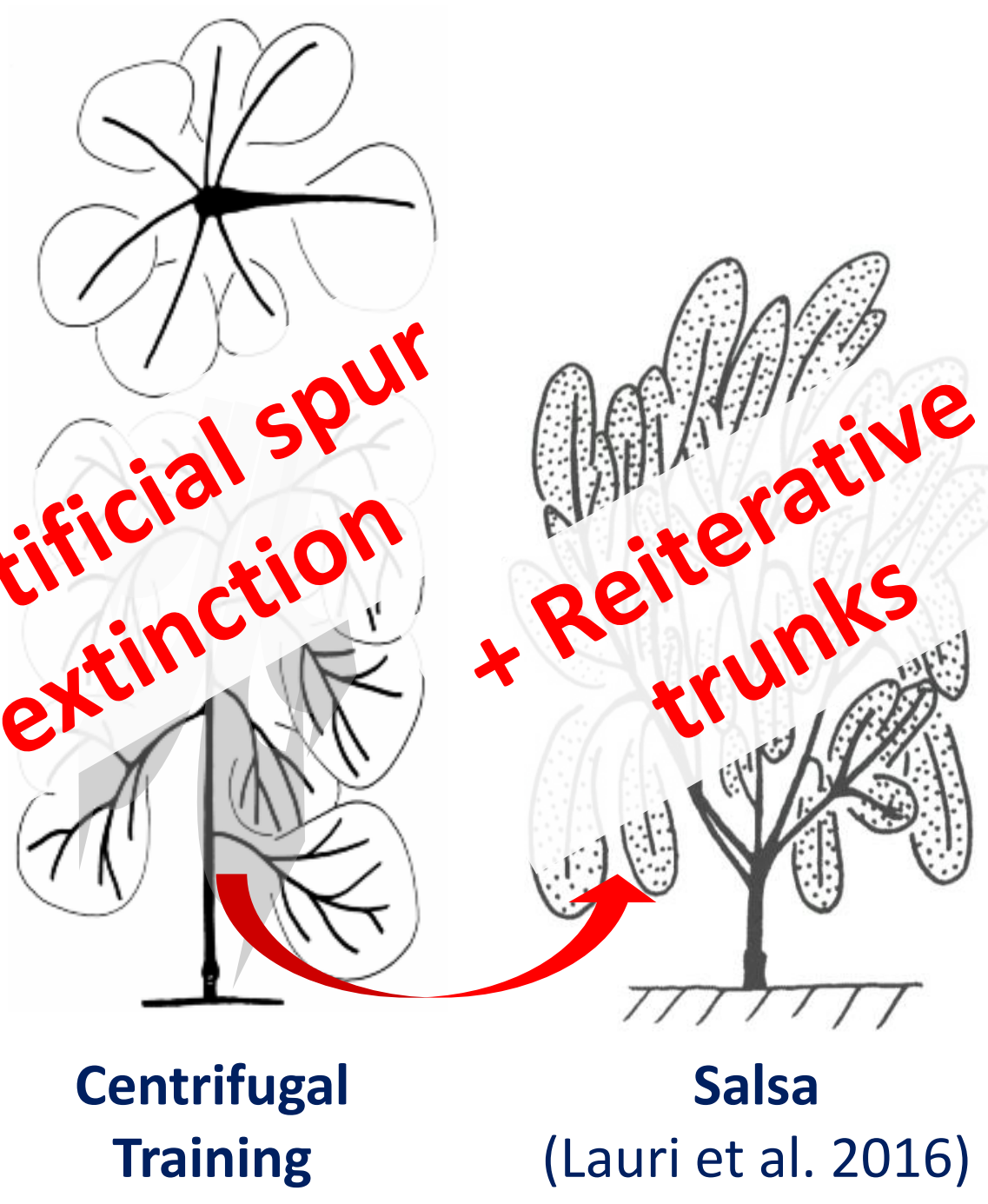
(Lauri 2009)

Paradigm:

" reiterative trunkfruiting spur $\|_{12}$ 


\section{The need to adapt to the cultivar}

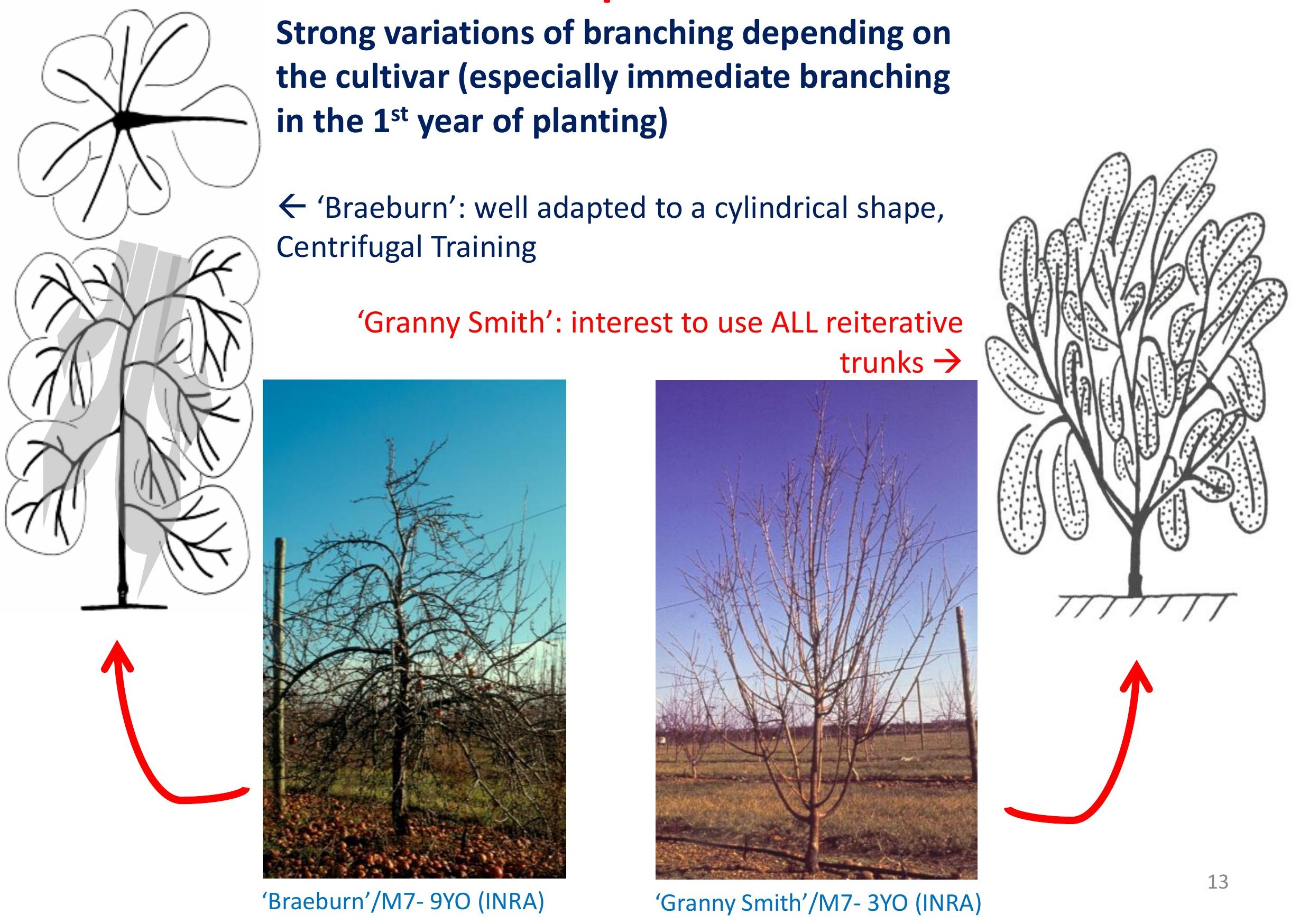




\section{A Tree in a System}

Monocropping / monocultivar orchards High performance ... with external resources as needed Intensive inputs: water, fertilizers, phytosanitary treatments $\Leftrightarrow$ A societal concern: pollution, leaching ... 


\section{Are there alternatives?}

Can we develop agroforestry systems (AFS) to buffer such externalities?

1, to mitigate climate extremes combining timber-trees above fruittrees.

A long-term timber-tree is more prone to buffer extreme climatic events than an annually fruiting tree (Stigter et al. 2011, Shoeneberger et al. 2012).

2, to increase biodiversity to better fight pests and pathogens (Lin 2011; Simon et al. 2016).

(): Such systems can increase productivity per land area, concept of LER (Land Equivalent Ratio): area of single-crop farming needed to produce the same amount of production (fruit, wood, grain) as 1 ha of agrosystem (eg, wheat-maize, Zhu et al. 2015; Rapidel et al. 2015; Gaba et al. 2015). 


\section{LER of AFS are usually more than 1}

\section{$\leftarrow$ optimization of space and time.}

Example:

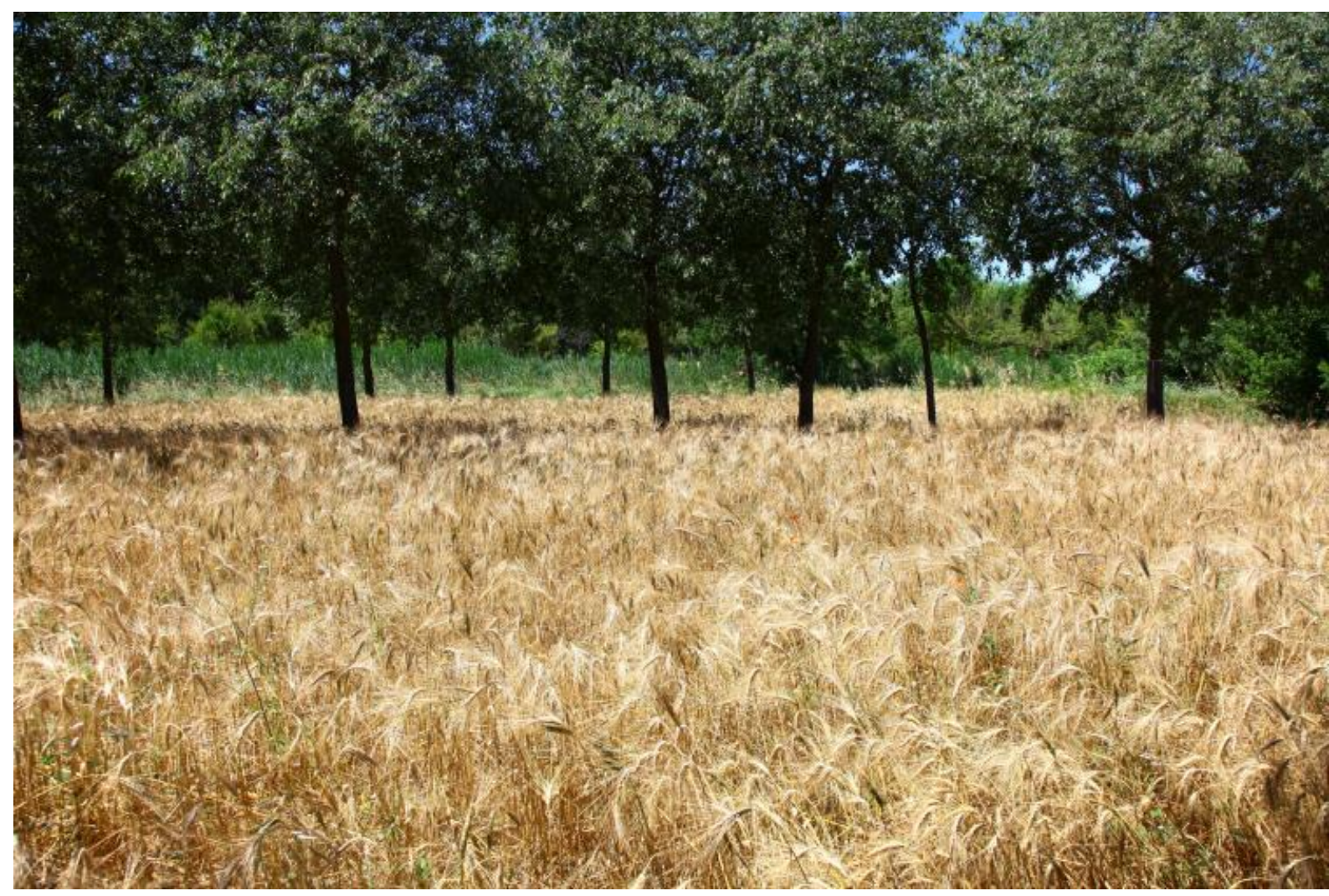

Production of timber-trees + barley $>$ Production of timber-trees alone + of barley alone

$\Leftrightarrow$ Use on the inter-row space otherwise not used, and during the whole growing season 


\section{AFS: traditional systems all over the world}

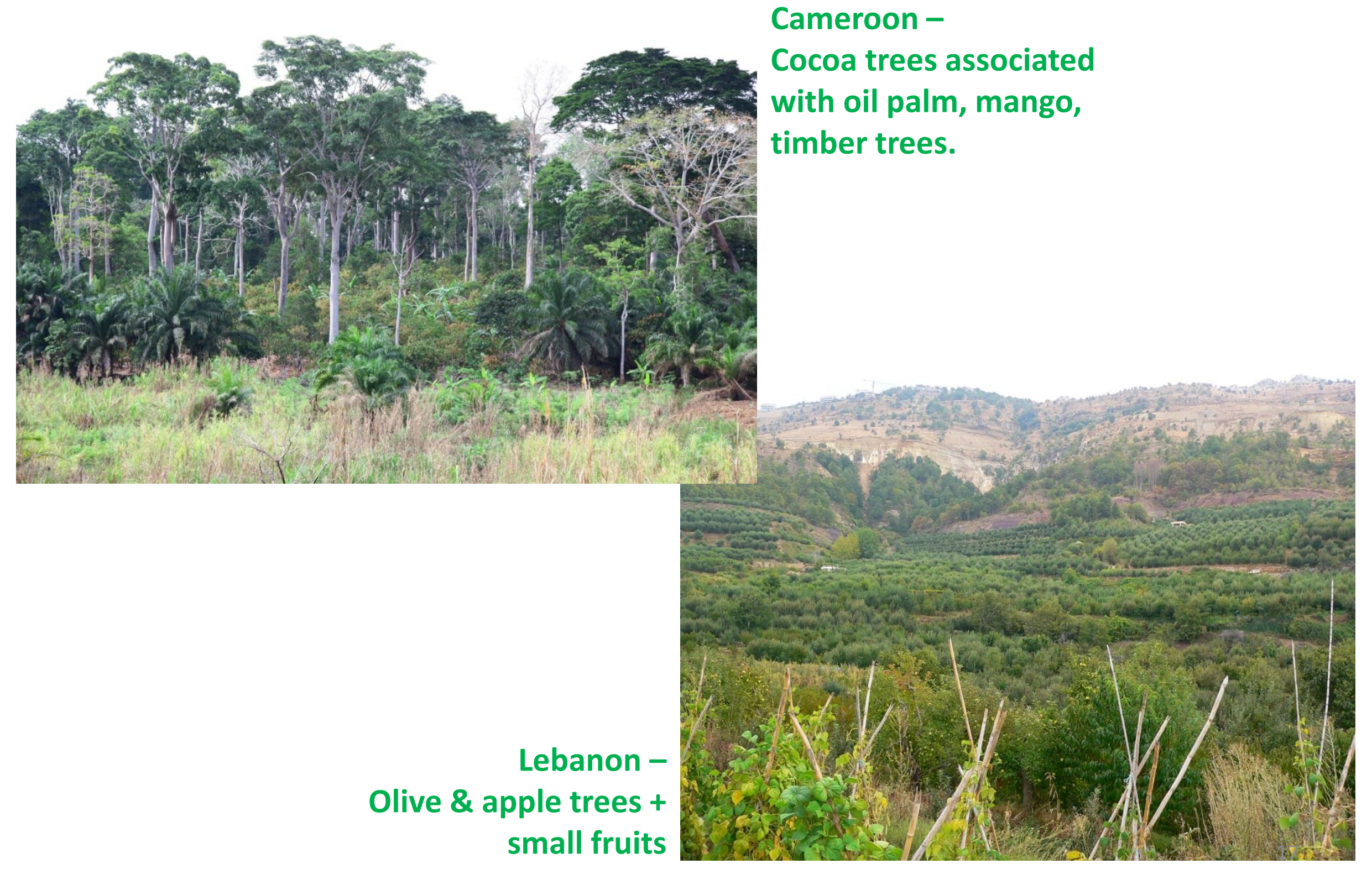


(:) European programme - CO FREE (Copper Free), 2012-2016. http://www.co-free.eu/index.php/co-free-project-details

Objective: Development of strategies for copper-free production

AFS as a means to reduce the use of copper

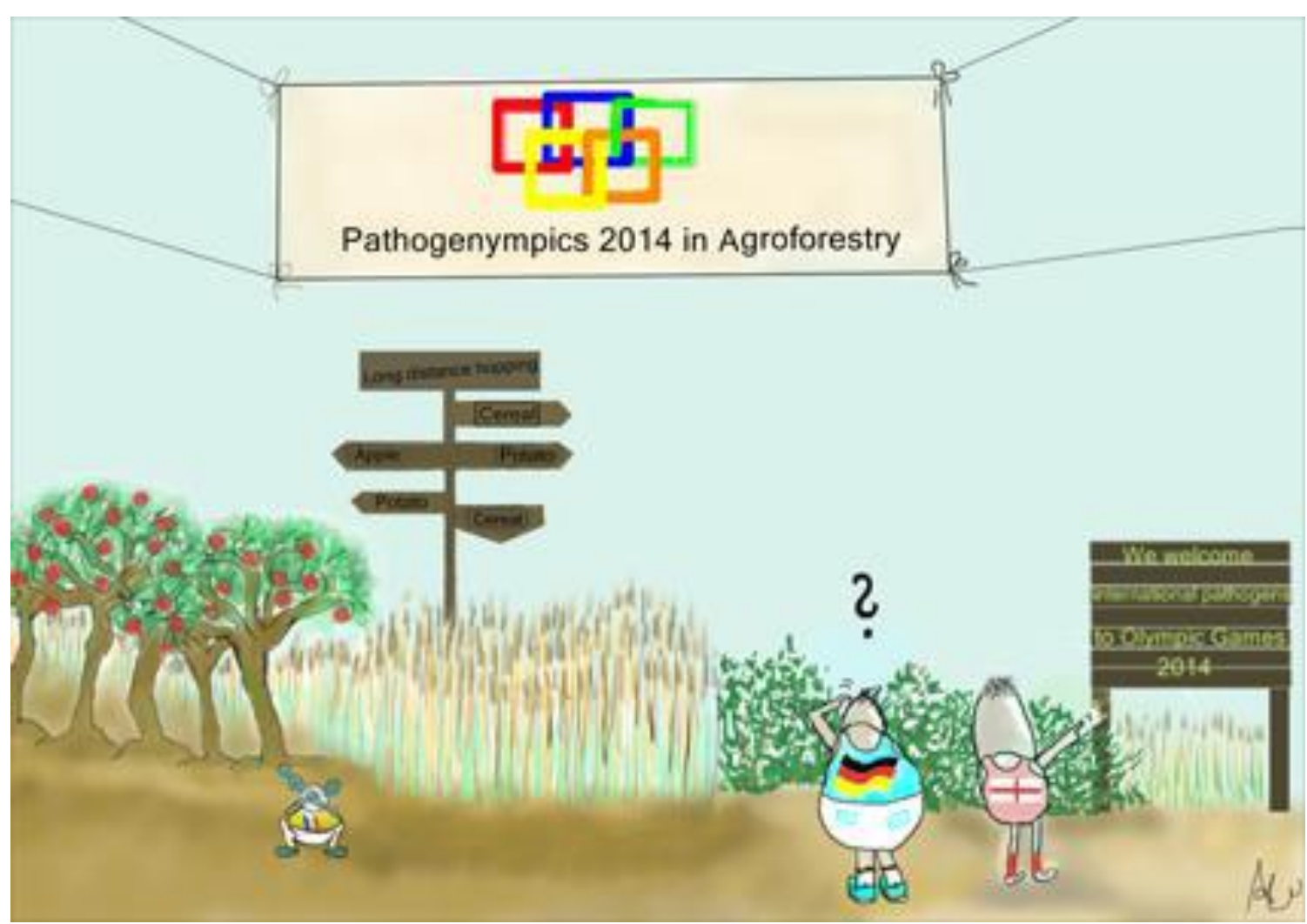

Eg, apple - Venturia inaequalis (Scab). Playing with lower tree densities. 
(:) USA - "A plan to broaden Midwest agroforestry via tree crops and multifunctional woody polyculture" - Fruit-trees as a component in multifunctional agro-ecosystem (Revord et al. 2015)
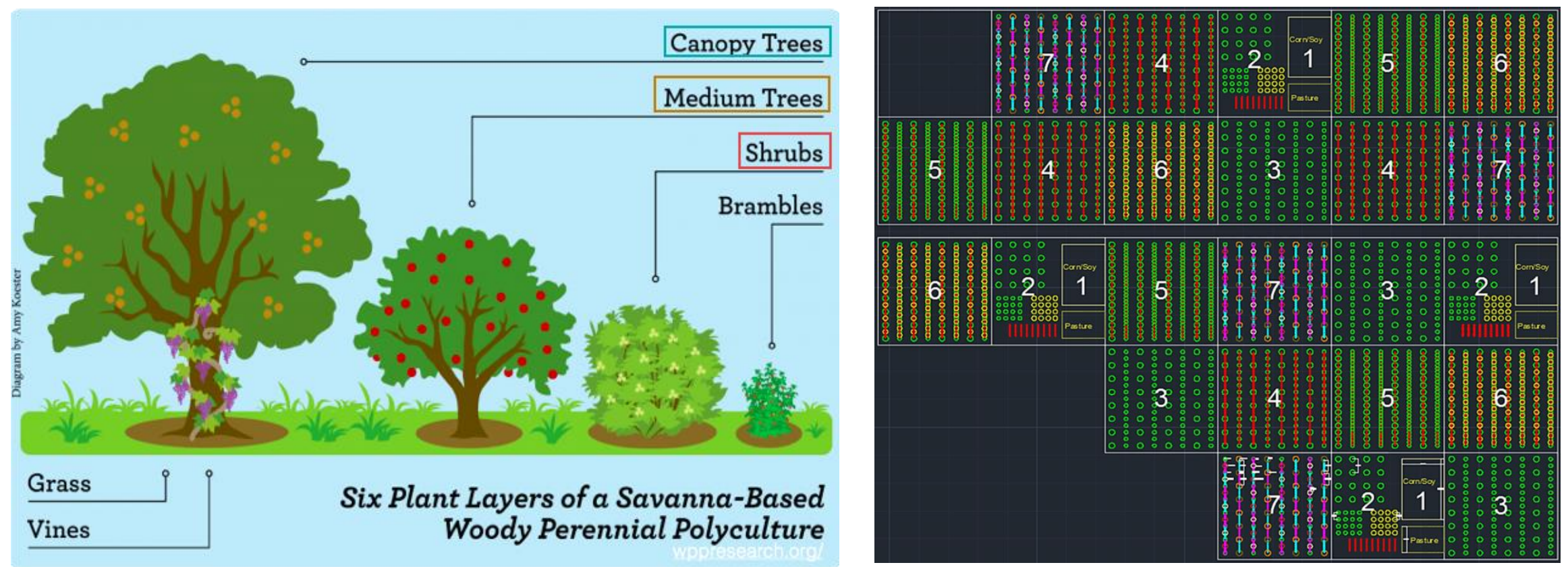

Various combinations of fruit species, with annual plants

$\stackrel{r}{\rightarrow}$ Pest and disease issues 


\section{Building AFS for apple trees:}

Increasing functional biodiversity

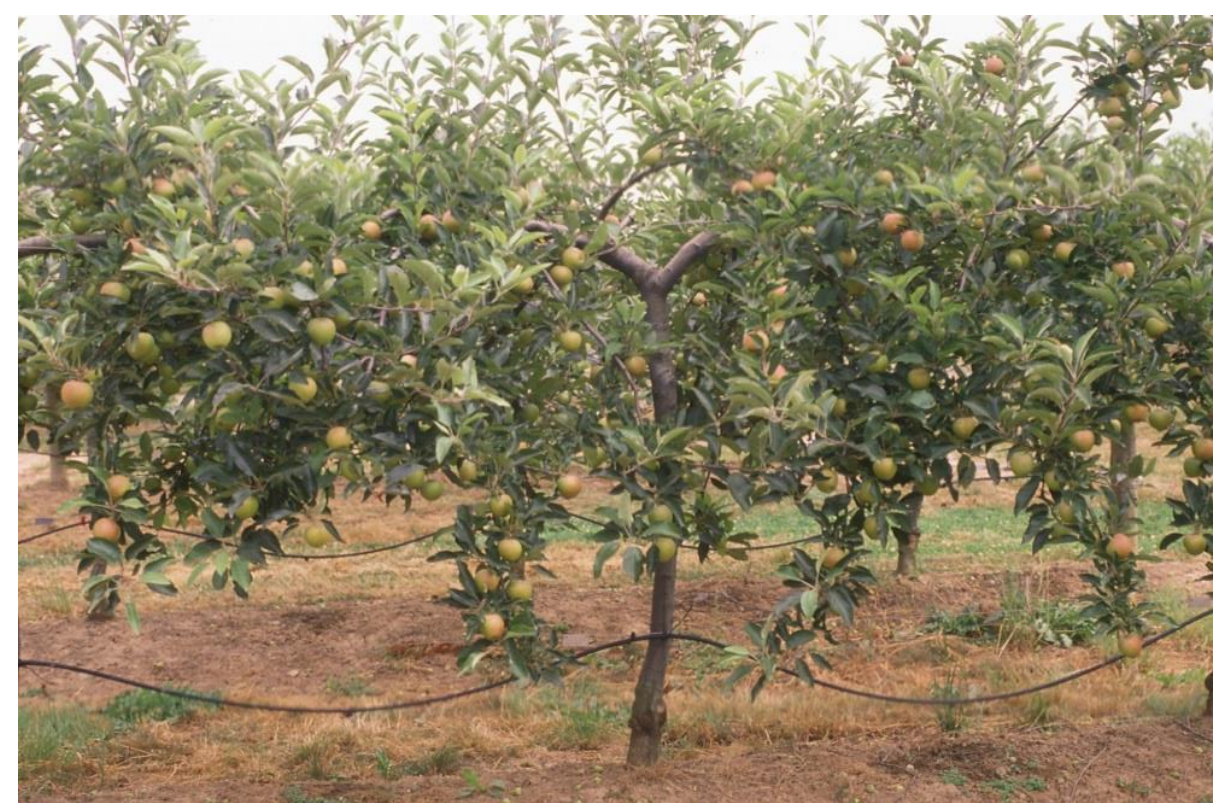

In the past: the orchard had to be " clean " (no grass in the alley!)

Grass alleys as a biocontrol against pests and diseases

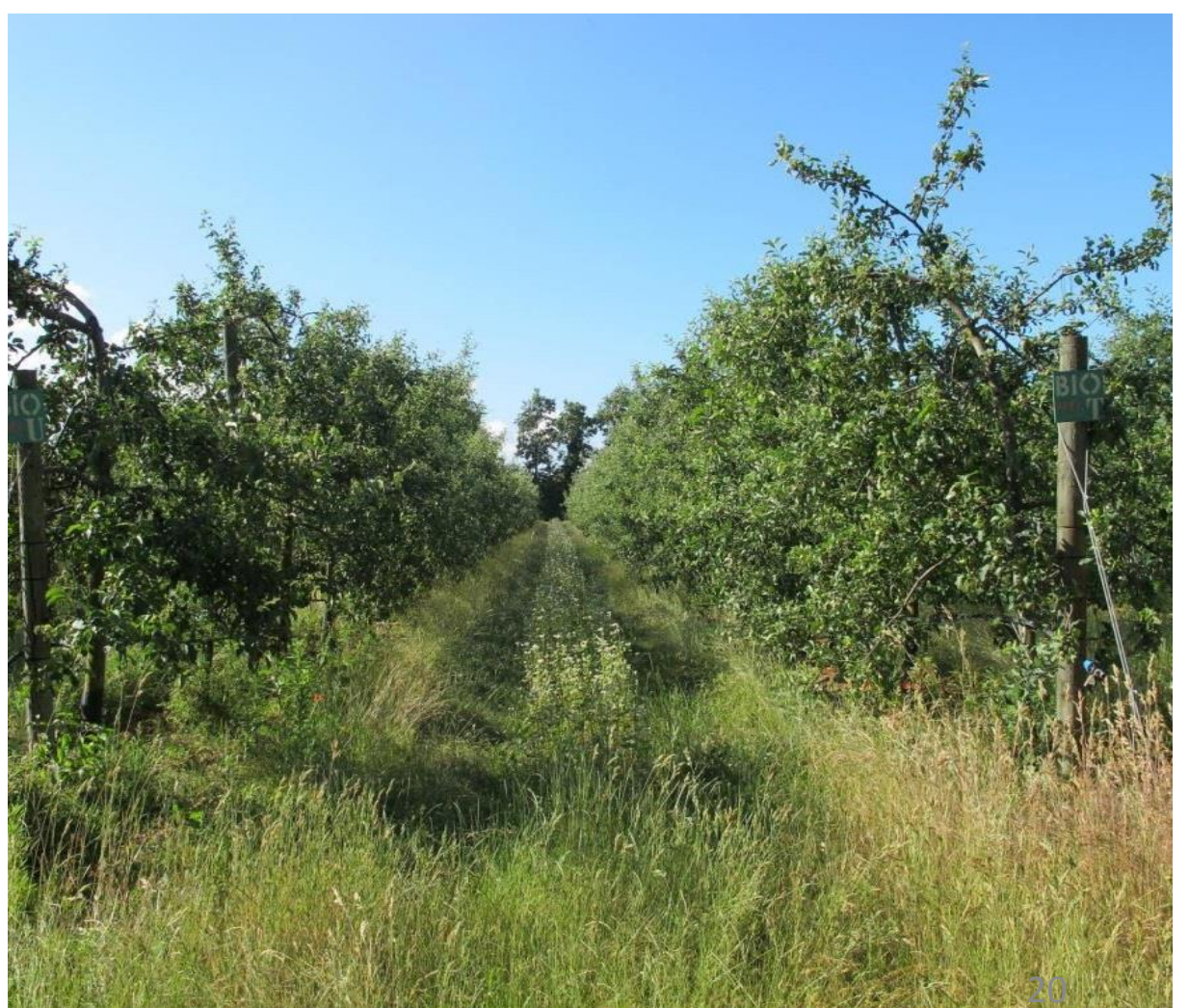


Annual and perennial plant assemblages as a way to foster,

- bottom-up and top-down processes in the food web,

- barriers and dilution effects,

$\leftrightarrow$ to control pests and diseases and to decrease pesticide use on fruit-trees.

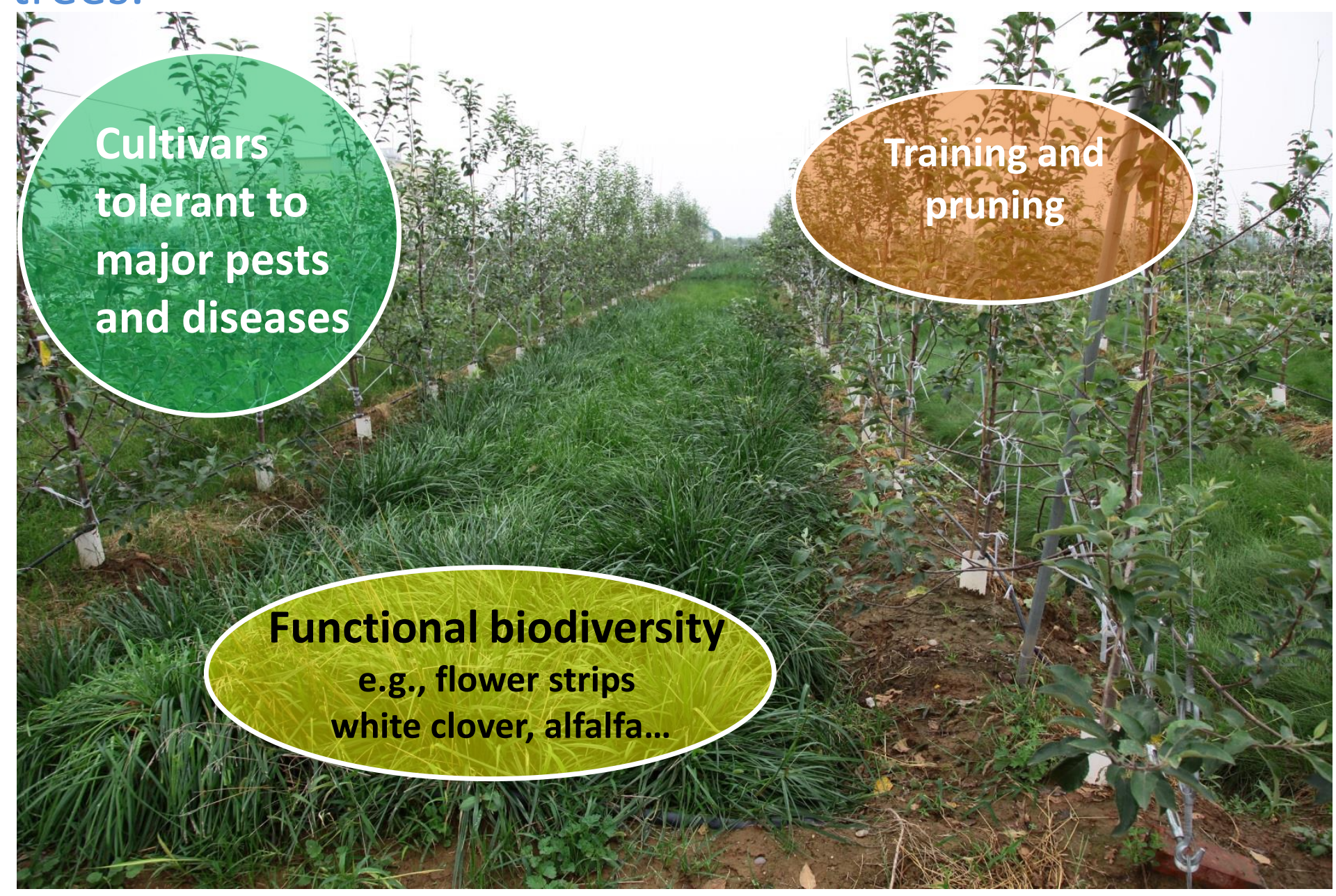




\section{Going further: interest to introduce larger trees (timber or nut)?}

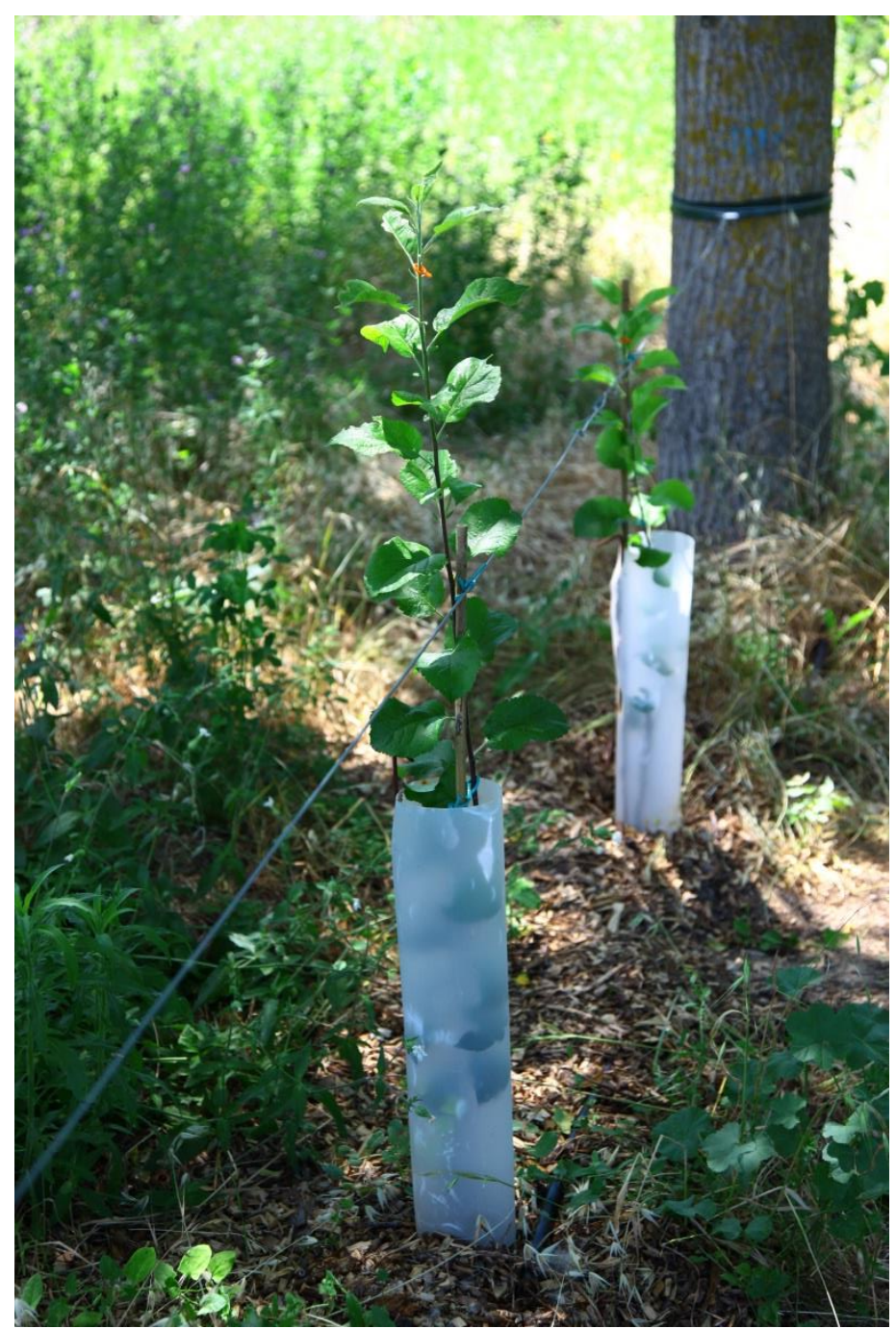

$\nearrow$ Biodiversity AND $\pi$ LER:

3 vertical strata:

- Herbaceous:

annuals: wheat in rotation with

other crops

OR perennials: alfalfa...

- Woody perennials:

- Apple

- Timber / nut-trees 


\section{Scientific and practical issues raised by AFS}

AFS increase interactions between plants: good or bad? $\rightarrow$ Classical research framework: competition OR facilitation

Aboveground (light):

Competition AND facilitation: interest to decrease photooxidative damages and sunburn on the apple.

(i) A good alternative to shade nets
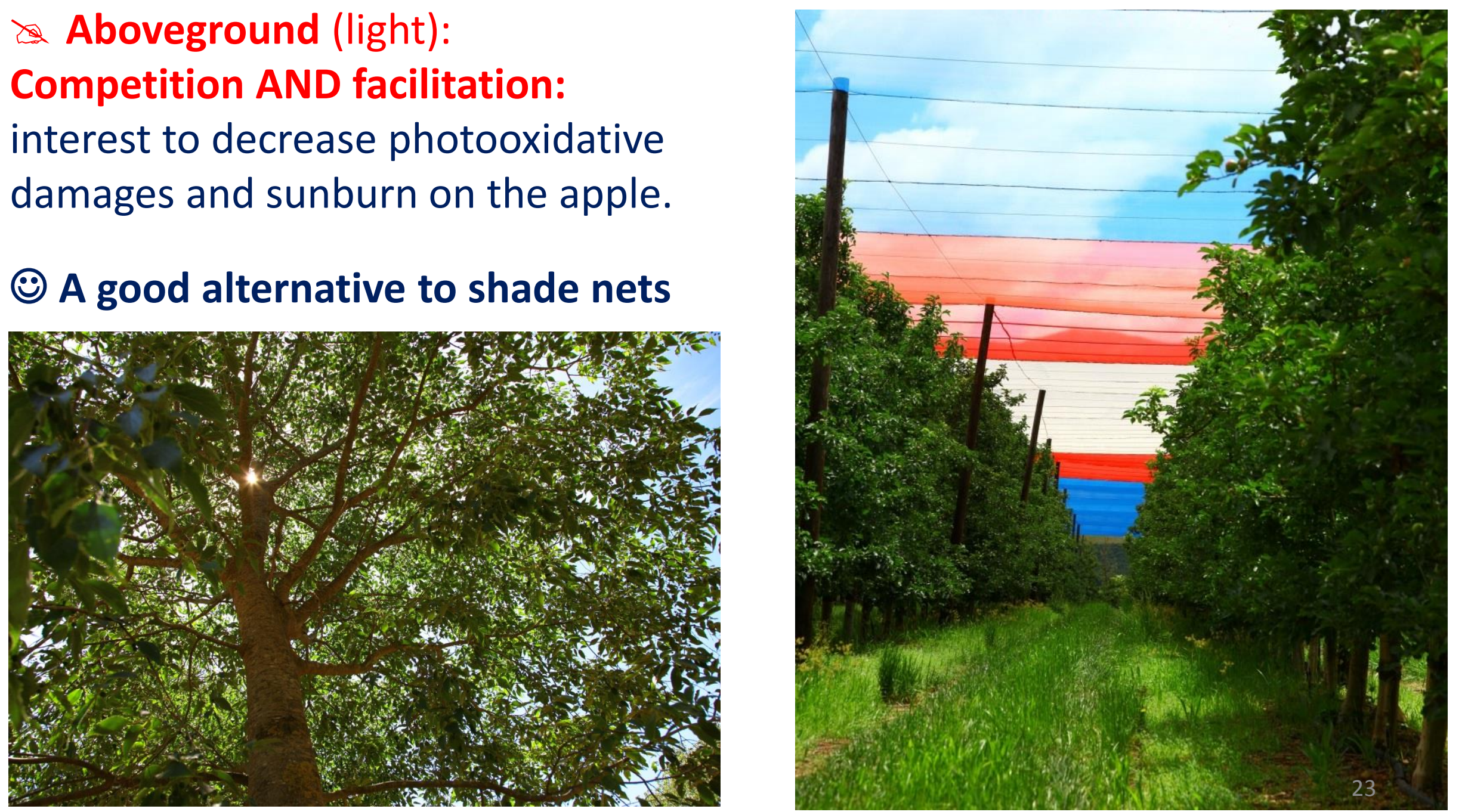


\section{Scientific and practical issues raised by AFS}

1 - Management of apple tree architecture ( $\pi$ tree porosity to light).

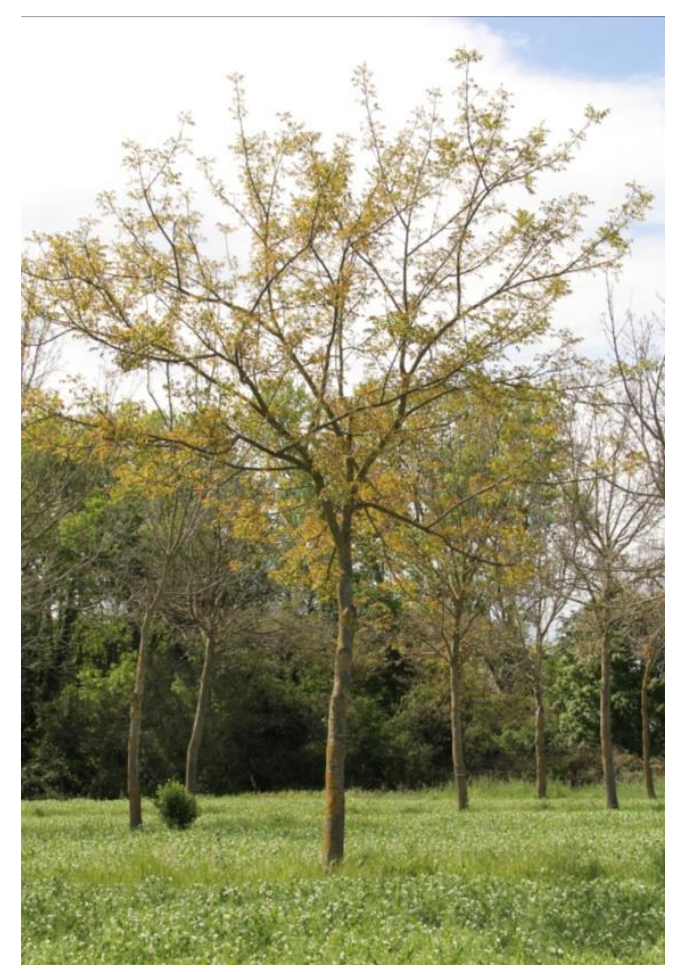

Free standing walnut
2 - Pruning of the timber tree to control shading on the apple and herbaceous in the lower strata

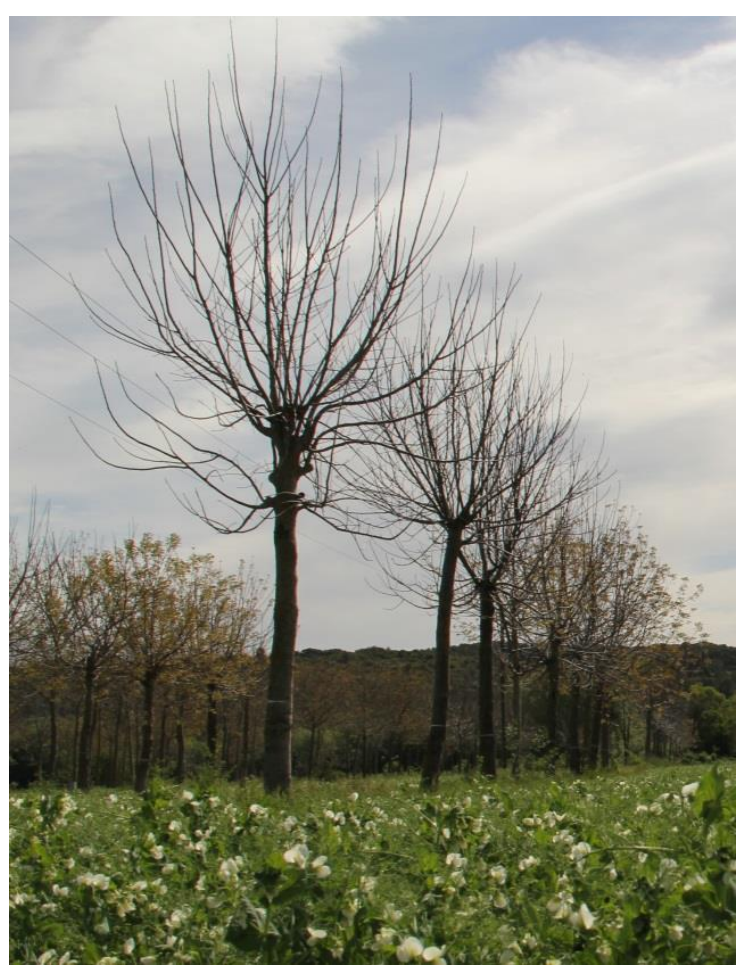

Pollarded walnut 


\section{Scientific and practical issues raised by AFS}

Belowground (water, nutrients): Competition:
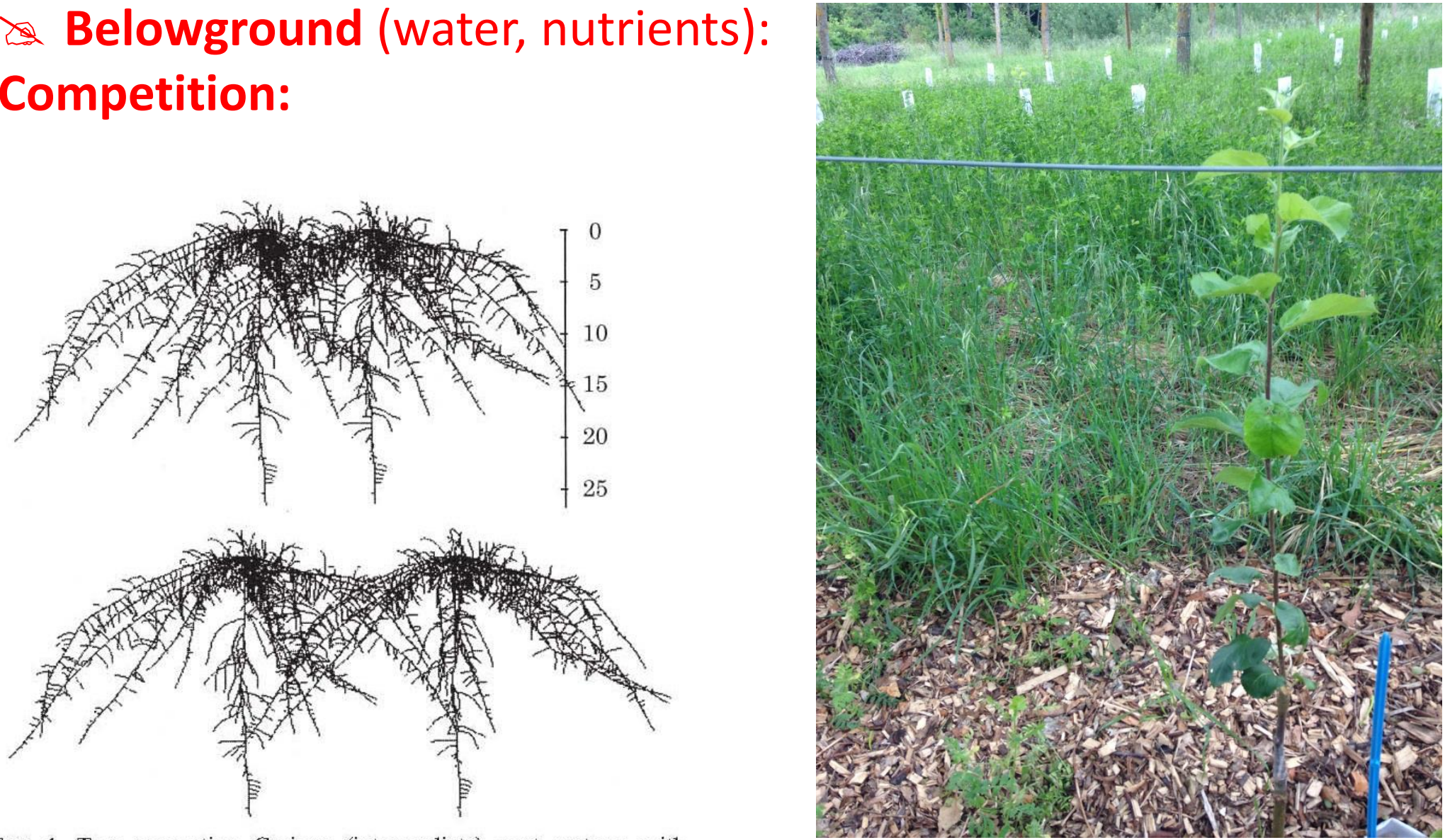

FrG. 4. Two competing Carioca (intermediate) root systems with different distances between plants (axis shown in $\mathrm{cm}$ ).

\section{Facilitation:}

(Rubio et al., 2001)

Leguminous plants: tree or herbaceous

Eg, alfalfa - apple 


\section{AFS, agrosystems, inter-cropping, relay-}

cropping ...: new contexts for new researches

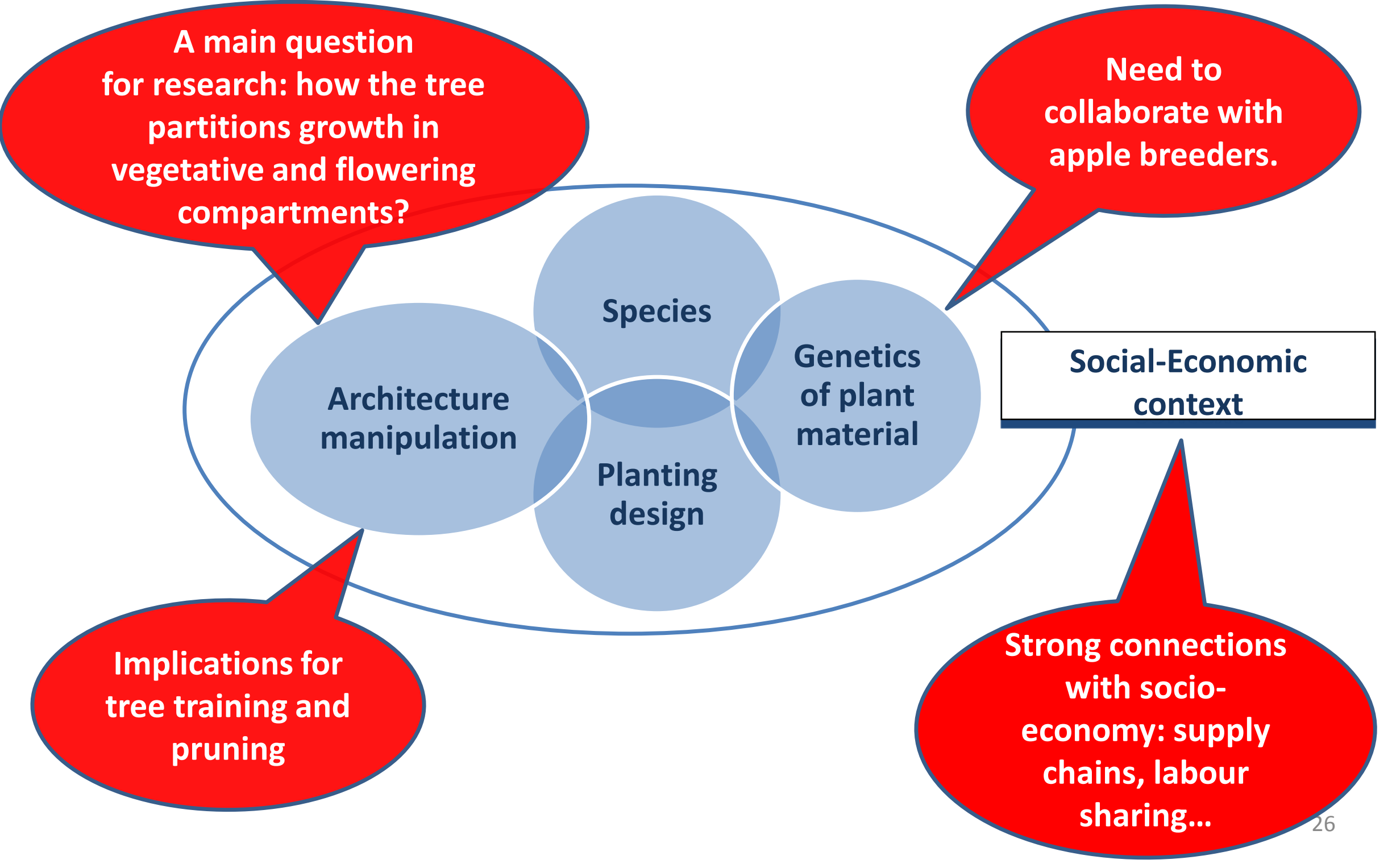




\section{Thank you Xie Xie}

Merci

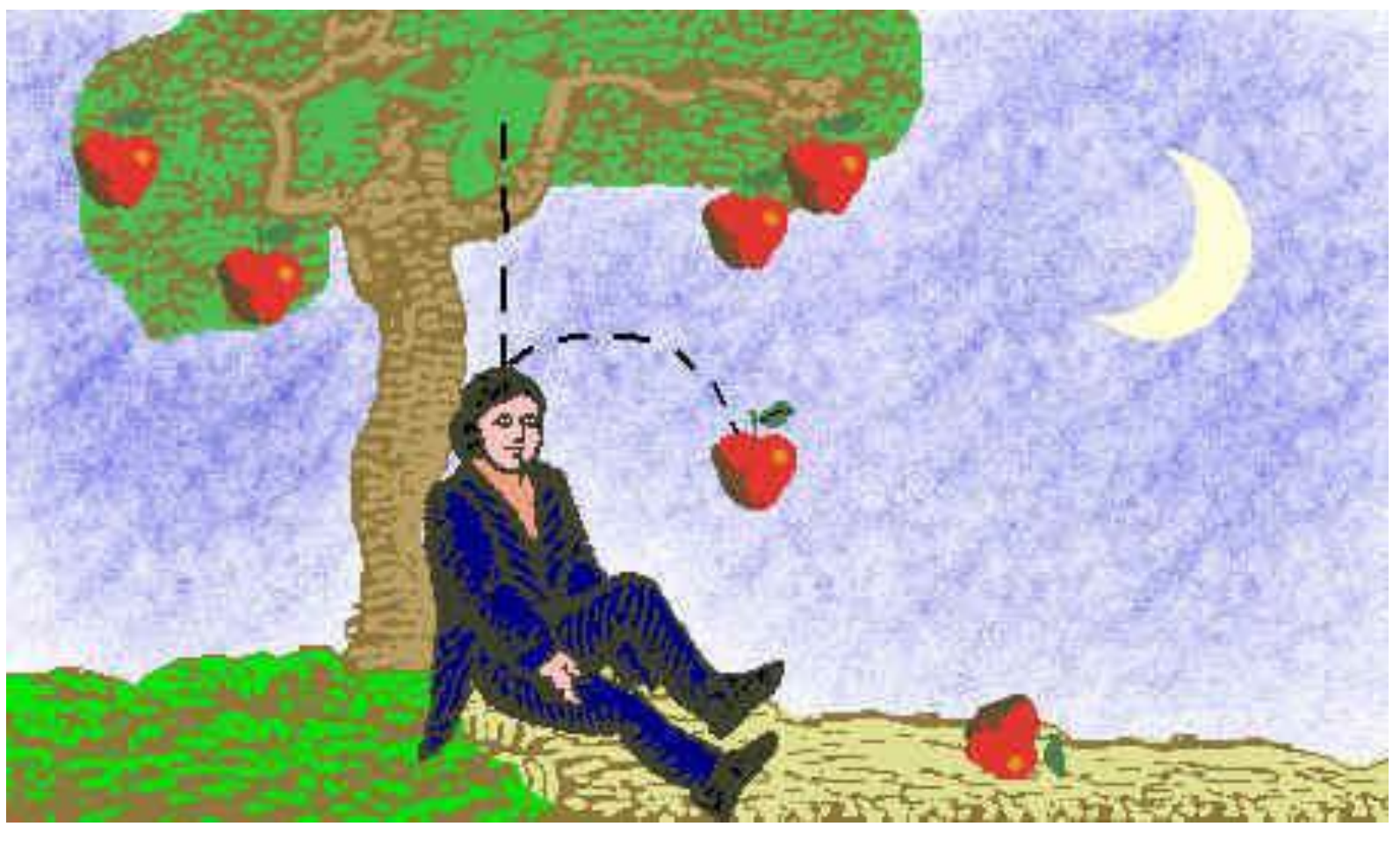

lauri@supagro.inra.fr 